\title{
Challenges with use of risk matrices for geohazard risk management for resource development projects
}

\author{
M Porter BGC Engineering Inc., Canada \\ M Lato BGC Engineering Inc., Canada \\ P Quinn BGC Engineering Inc., Belgium \\ J Whittall BGC Engineering Inc., Canada
}

\begin{abstract}
Geohazards comprise a subgroup of natural hazards associated with geotechnical, hydrotechnical, tectonic, snow and ice, and geochemical processes that can pose a threat to worker and public safety, asset integrity, and asset management lifecycle cost. Like for most types of threats, the risks from geohazards can be assessed qualitatively or quantitatively and used to inform a geohazard management program.
\end{abstract}

Most mining companies use risk matrices to aid in the assessment, prioritisation, communication and management of corporate risks. These matrices use standardised descriptions of likelihood and consequence to help users assess risks of negative outcomes to health, safety, the environment, assets, and reputation, and are tailored to each organisation's types of risk exposure and level of risk tolerance.

Geohazards and related geotechnical failures can represent low-probability, high-consequence events that plot in the highest risk zones of most corporate risk matrices. Variability in spatial and temporal probabilities for people and infrastructure exposed to geohazards can have a large influence on risk exposure, and this can be challenging to assess and communicate effectively with some risk matrices. Risk is scale-dependent: the business risk due to rockfall from a single slope along a mine access road is vastly different than the total risk due to rockfalls from all slopes along that road, yet guidance is often missing on how the risks from these scenarios should be plotted on a risk matrix. These and other pitfalls associated with use of corporate risk matrices for informed geohazard management are explored.

Keywords: geotechnical, geohazard, risk matrix, risk assessment, risk communication

\section{Introduction}

Most owners and operators of energy, resource development and transportation infrastructure use risk matrices to aid in the assessment, prioritisation and management of risks. These matrices use standardised descriptions of likelihood and consequence to characterise risks of negative outcomes to health, safety, the environment, and assets. The matrices are usually tailored to each organisation's types of risk exposure and level of risk tolerance. They often become embedded in corporate standards and are used to inform the wide range of risk management tasks that are required throughout each organisation's planning and operational activities.

Geohazards comprise a subgroup of hazards associated with geotechnical, hydrotechnical, tectonic, snow and ice, and geochemical processes that can pose a threat to worker and public safety, asset integrity, and asset management lifecycle cost. Geohazards may be present along linear infrastructure such as roads, railways and pipelines, within the abutments and reservoirs of dams, and affect other infrastructure and assets associated with resource development. As with most types of threats, the risks from geohazards can be assessed qualitatively or quantitatively with a degree of accuracy and precision that will tend to improve over time with improvements in experience, data, and methods of analysis. 
Companies often try to present the results of geohazard risk assessments and carry out risk management activities in ways that align with their corporate risk matrices, even though the matrices are usually only intended for screening-level assessments. Perhaps this is because risk matrices appear simple and logical, seem to allow for an apples-to-apples comparison of geohazard risks with risks from other threats, and because a standard risk matrix that is applied consistently across an organisation offers the promise of improved risk communication and decision-making. However, there are several pitfalls associated with use of corporate risk matrices for geohazard management that owners and geohazard practitioners should be aware of and strive to overcome.

This paper provides a brief introduction to geohazards and ways that geohazards impact resource development projects. It then outlines a risk formulation that is commonly used to estimate the safety and financial risks posed by geohazards. Risk matrices are introduced, and several challenges that are often encountered when using risk matrices for geohazard management are described and guidance on how to overcome some of these challenges is provided. The objective of this paper is to improve geohazard assessment and risk communication practices within the mining industry.

\section{Geohazards}

\subsection{Definition and types}

Geohazards can affect public safety, reduce the safety of construction or operational personnel, impact construction schedules and costs, threaten the integrity of assets and associated infrastructure, and impact the environment (Porter et al. 2014). Most are processes triggered or accelerated by floods, storms, freeze/thaw or seismic activity, by progressive weakening of soil or rock over time, or by excavations, placement of fill, alteration of drainage or other human activities.

A partial list of geohazards that may need to be accounted for in resource development projects, and within their risk management programs, is provided in Table 1.

Table 1 Partial list of geohazard types

\begin{tabular}{|c|c|c|c|}
\hline Hazard class & Type/name & Hazard class & Type/name \\
\hline \multirow[t]{8}{*}{ Geotechnical } & Frost heave & \multirow[t]{8}{*}{ Hydrotechnical } & Debris flow \\
\hline & Thaw settlement & & Scour \\
\hline & Solifluction & & Channel degradation \\
\hline & Rockfall & & Bank erosion \\
\hline & Rock slide/creep & & Encroachment \\
\hline & Earth slide/creep & & Avulsion \\
\hline & Earth flow & & Shoreline wave erosion \\
\hline & Debris slide & & Tsunami/landslide-generated waves \\
\hline \multirow{5}{*}{$\begin{array}{l}\text { Seismic and } \\
\text { tectonic }\end{array}$} & Strong ground motion & \multirow{5}{*}{$\begin{array}{l}\text { Other ground } \\
\text { movement }\end{array}$} & Surface water erosion \\
\hline & Liquefaction & & Groundwater erosion \\
\hline & Lateral spreading & & \multirow{3}{*}{$\begin{array}{l}\text { Ground subsidence } \\
\text { (karst/mines/groundwater } \\
\text { withdrawal/soft soils) }\end{array}$} \\
\hline & Surface fault rupture & & \\
\hline & Volcanic eruption & & \\
\hline Snow and ice & $\begin{array}{l}\text { Snow avalanche } \\
\text { Icefall and ice avalanche }\end{array}$ & Geochemical & $\begin{array}{l}\text { Acid rock drainage and metal } \\
\text { leaching }\end{array}$ \\
\hline
\end{tabular}




\subsection{Impacts to resource development projects}

Geohazards can impact resource development at all project stages. During exploration, geohazards can threaten the safety of personnel conducting field mapping, access trail construction, and drilling. At these early stages of project development, little is often known about the geohazard types and triggering processes affecting an area, and geotechnical and geohazard specialists are often not involved in the planning and execution of the exploration activities.

As projects advance to later stages of exploration, design, and construction, the number of personnel onsite increases and the seasonal duration of site activities tends to expand. This increases exposure time for people and equipment to geohazards, and may increase the types or frequencies of geohazards that are encountered. For example, mineral and geotechnical exploration in mountainous terrain conducted in early spring or late fall/winter may be exposed to snow avalanche hazard which is a lesser concern in the summer months. As these projects advance, so will site disturbance by way of construction of access roads, trails, drilling platforms, exploration adits, and so forth. Cuts, fills and drainage alteration associated with these activities can also increase the potential for geohazards.

Geohazards can pose many types of risk to operations. Linear infrastructure such as access roads, rail lines, powerlines, diversion channels, conveyors, and pipelines transporting water, tailings and mine concentrate, are often exposed to a wide range of geohazard types that can threaten asset integrity and the safety of maintenance and operational personnel. Occasionally, geohazards such as landslides will impact plant sites, tailings facilities or other critical mine infrastructure.

Some types of geotechnical failures, such as the failure of dams, waste dumps and pit slopes, share similarities with geohazards and their risks are sometimes assessed and managed using similar techniques.

Geohazards can also impact performance objectives during closure. Subsidence or ground cracking from slope movement can impair soil covers and water conveyance structures. Wave erosion along shorelines can alter water quality in in-pit lakes. Engineered slopes will, over the course of time, be subjected to extreme weather events and large earthquakes that can result in erosion or slope failure. Long-term changes in temperatures and precipitation patterns associated with climate change may alter geohazard exposure and add uncertainty to risk assessment for closure.

\subsection{Magnitude-frequency considerations}

Geohazard processes such as landslides, floods and earthquakes usually exhibit a magnitude-frequency relationship (e.g. Figure 1). For a given hazard type affecting a site, larger geohazard events tend to occur less frequently than smaller events.

While individual smaller events usually pose less safety risk and cause less damage to infrastructure, they tend to occur much more frequently than larger events. As a result, the smallest (and most frequent) event that can lead to a credible loss scenario will often be the dominant source of risk, particularly along transportation corridors. There are exceptions, however. For example, if infrastructure is designed to accommodate a certain magnitude of event (such as a design flood level), events of smaller magnitude might be expected to cause minor damage that can be repaired through routine maintenance activities, while events with a larger magnitude may overwhelm mitigation measures (such as diversion channels or berms) and cause significant loss.

The mobility (velocity and runout distance) of some types of landslides increases with event magnitude. For people or infrastructure located some distance from the landslide source, the spatial probability of impact might be negligible for low-magnitude events but much higher for larger, less-frequent events. 


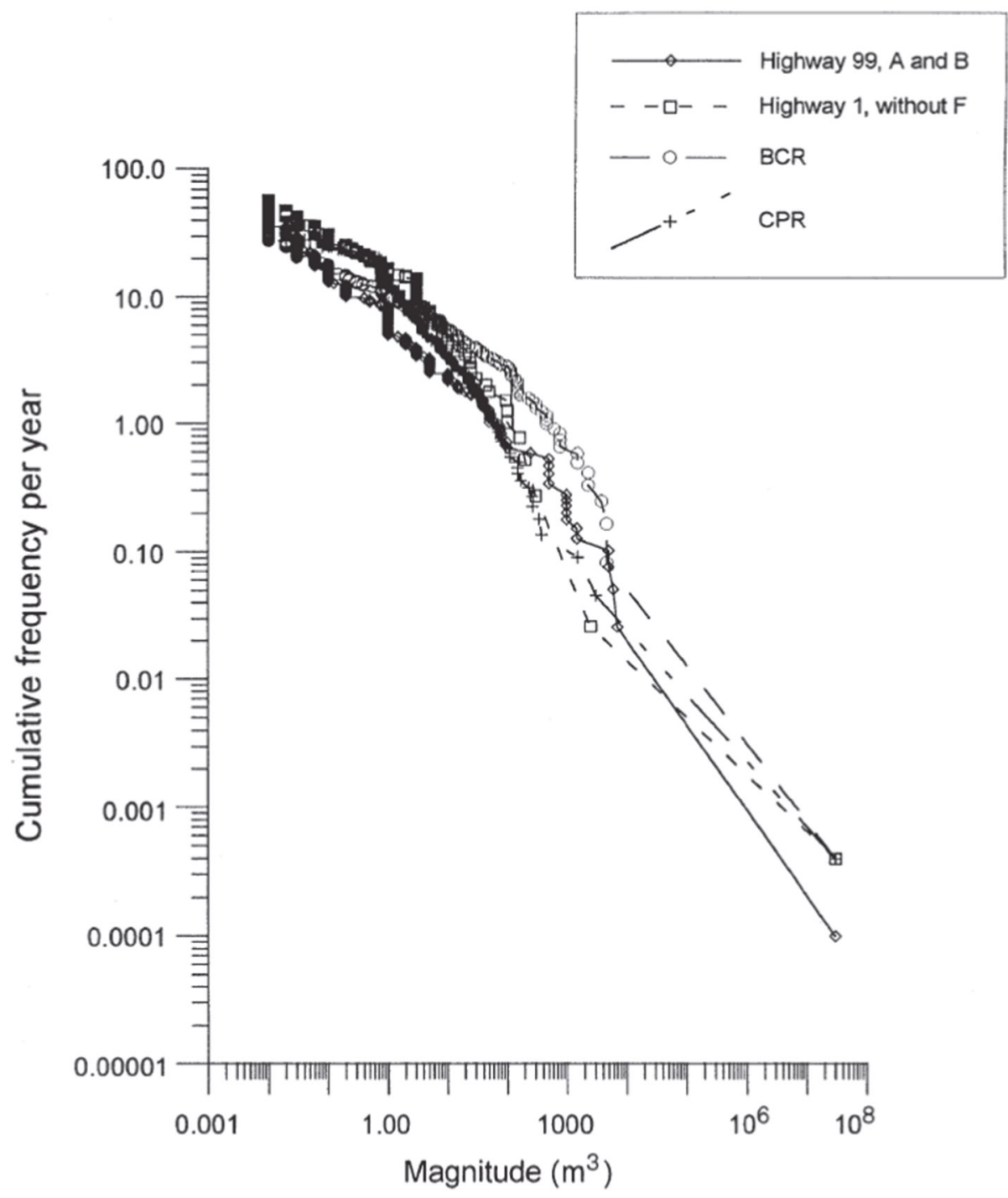

Figure 1 Magnitude-frequency relationships for rockfalls and rock slides along transportation corridors in southwestern British Columbia, Canada (Hungr et al. 1999). BCR = British Columbia Railway, $\mathrm{CPR}=$ Canadian Pacific Railway

\subsection{Risk formulation}

In the context of geohazard assessment and management, we define risk as the 'expected loss' from a geohazard process. For consistency, risk is often expressed as the annual probability of a specific negative outcome. For example, if the geohazard process of interest is landslides and we are concerned about life safety, risk might be defined in terms of the expected number of fatalities per year caused by landslides.

Risk is usually estimated as the product of hazard likelihood and consequence, where hazard likelihood is the probability (or frequency) of potentially damaging phenomena occurring, and consequence is the negative outcome (or loss) that results. Risk, or expected probability of loss, $\mathrm{P}(\mathrm{E})$, from multiple geohazard scenarios (hazard types and/or event frequencies and magnitudes) affecting an element at risk, can be estimated using the formulation presented in Figure 2. 


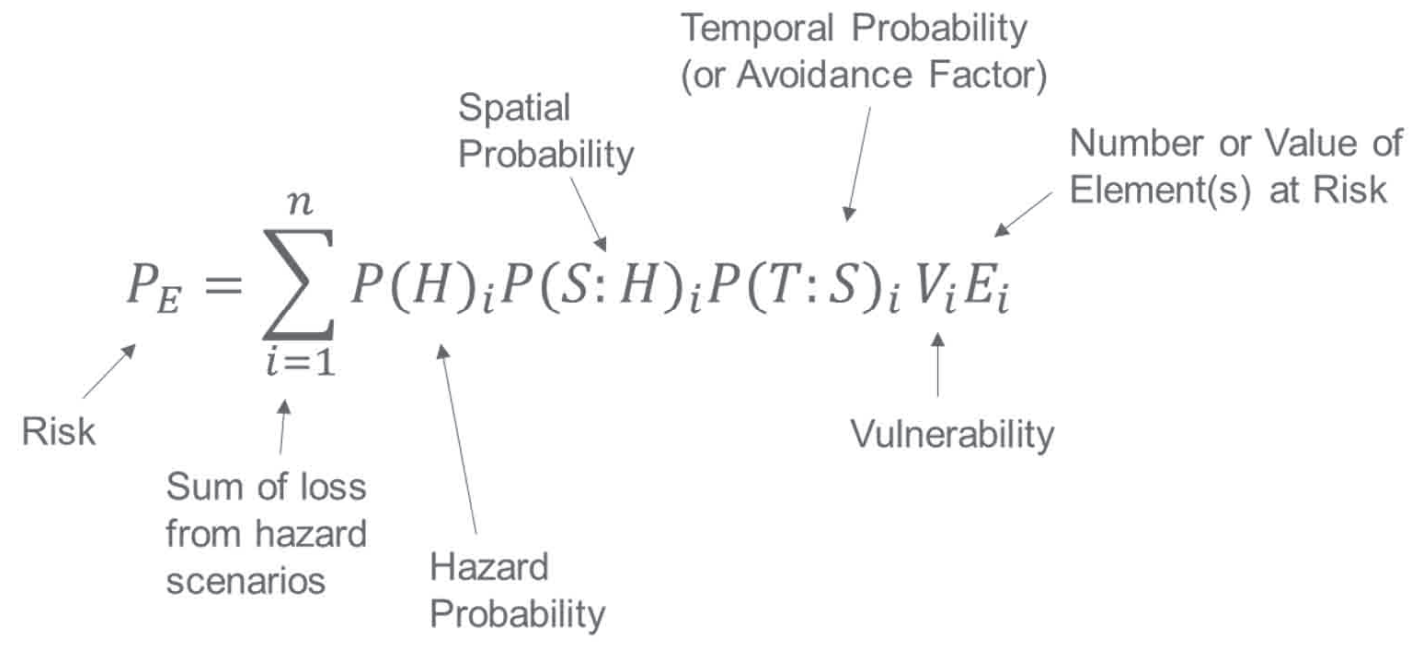

Figure 2 Formulation for estimating expected loss (risk) from the geohazard scenarios $\mathrm{i}=1$ through $\mathrm{n}$ potentially affecting an element at risk

The following simplified example illustrates the estimation of rockfall safety risk along a transportation corridor.

For a geohazard to result in a loss, the following must generally be true:

- A geohazard of sufficient magnitude to cause a loss must occur. This is commonly referred to as the hazard probability, $\mathrm{P}(\mathrm{H})$. For example, if rockfalls of a certain volume (say one to five cubic metres) from a specific access road cut occur once every 15 years, on average, rockfall would have an approximate annual probability of $1 / 15$, or $6.7 \times 10^{-2}$.

- The geohazard must reach a location where it can impact the element(s) at risk. This is commonly referred to as the spatial probability, $\mathrm{P}(\mathrm{S}: \mathrm{H})$. For example, the rockfall described above might have to travel down a cut slope and through a ditch to reach the running surface of the road, and given the cut and ditch geometry, perhaps four out of five rockfalls of this magnitude are expected to be contained by the ditch. This yields a conditional spatial probability of that type of rockfall reaching the running surface of $1 / 5$, or 0.2 .

- The product of the two terms above (the hazard and spatial probabilities) provides an estimate of the annual probability of debris from that specific size of rockfall landing on the running surface of a road $\left(1 / 15 \times 1 / 5=1.3 \times 10^{-2}\right)$. This is sometimes referred to as 'encounter probability'.

- The element(s) at risk must be present within the zone of influence of the geohazard when the geohazard occurs, which is referred to as the temporal probability, $\mathrm{P}(\mathrm{T}: \mathrm{S})$. Continuing the example above, the proportion of time that road users occupy the potential zone of influence of the rockfall might only be $1 \%$, which yields a conditional probability of $1.0 \times 10^{-2}$.

- As an alternative to the temporal probability, a loss can also occur if the element(s) at risk encounter the geohazard (or damage caused by it) after the geohazard event has already occurred with sufficient speed that impact cannot be avoided. This can be accounted for using what is sometimes referred to as an avoidance factor, AF. For example, if the rockfall scenario described above occurs in a location with limited sight distance, and where the travel speed is such that the average road user has a $90 \%$ chance of safely avoiding the rockfall debris on the road, the avoidance factor (i.e. the conditional probability that the geohazard will not be avoided) would be 0.1 .

- The way the geohazard impacts the element(s) at risk, or the way the element(s) at risk impact the geohazard, must be sufficient to cause some expected degree of loss that ranges from almost no loss (conditional probability of loss near 0 ) to nearly complete loss (near 1 ). We refer to this as the vulnerability, V. Accident statistics and judgment might suggest that motor vehicle occupants struck 
by debris from a rockfall of a certain volume class while driving have an $80 \%$ chance of fatality, which implies a vulnerability of 0.8 . Conversely, when a motor vehicle impacts debris from that size of rockfall at speed, there might only a $20 \%$ chance of fatality $(V=0.2)$. Factors such as potential rockfall height and impact energy, posted road speed, and road embankment geometry may influence these vulnerability estimates.

- The element(s) at risk, or the consequences of their loss of function, must have some value, E. Often this is the number of people exposed, or the potential financial loss associated with infrastructure damage and loss of service. If the average number of motor vehicle occupants in our example is 1.5 , and we were interested in estimating the risk of fatality from rockfall, E would be equal to 1.5 . A more rigorous assessment would take into consideration the reasonable range of occupants that could be impacted by a rockfall event instead of just using the average value.

In our example, the expected life loss from rockfall debris landing on the running surface of the road would be the sum of:

- $1.2 \times 10^{-2}$ fatalities from the (unlikely) scenario where the debris falls on a moving vehicle (from the last three terms in the risk formulation and using temporal probability), with an annualised risk of $1.6 \times 10^{-4}$ fatalities per year.

- $3.0 \times 10^{-2}$ fatalities from the (more likely) scenario where a moving vehicle impacts the debris (from the last three terms in the risk formulation and using the avoidance factor), with an annualised risk of approximately $4.0 \times 10^{-4}$ fatalities per year.

As a result, the expected number of fatalities should rockfall debris land on the road is $4.2 \times 10^{-2}$. Another way of saying this is that the conditional probability of fatality, given the occurrence of rockfall reaching the road, is $4.2 \times 10^{-2}$. Accounting for the probability of this specific size of rockfall reaching the road, total safety risk in our example would be about $5.6 \times 10^{-4}$ fatalities per year, or about a 1 in 1,800 chance of a fatality per year for every year the road is in use.

Similar scenario analysis and mathematics can be used to explore potential geohazard risk in terms of maintenance and lifecycle costs, business interruption risk, etc.

To further round out our rockfall example, we would need to consider the safety risks associated with rockfalls less than $1 \mathrm{~m}^{3}$ and greater than $5 \mathrm{~m}^{3}$; in other words, the magnitude-frequency considerations that were discussed earlier. Event trees are often used to help develop and communicate the logic and ensure that the math conforms with certain probability rules (e.g. that conditional probabilities for mutually exclusive outcomes sum to 1.0).

Finally, because each of the parameters in the risk formulation is subject to uncertainty, risk assessment will often use sensitivity analyses or other techniques to explore the impact of some or all of those uncertainties on the estimated level of risk.

\section{$3 \quad$ Risk matrices}

In the authors' opinions, it is usually preferable to estimate geohazard risk using targeted quantitative or semi-quantitative methods that honour the risk formulation outlined above, and to use industry and international safety risk tolerance criteria and risk cost-benefit analyses to inform decision-making. However, there is often a desire to use corporate risk matrices to help assess, evaluate, communicate and manage the risks, at least at an initial screening level.

Risk matrices combine estimates of the likelihood of a negative outcome with estimates of the magnitude of consequence to arrive at an expression of risk. Figure 3 provides two hypothetical examples that include expressions of safety and financial risk. Often, risk matrices also facilitate assessment of social, environmental and other risk types. 


\begin{tabular}{|c|c|c|c|c|c|c|}
\hline \multirow{2}{*}{$\begin{array}{l}\text { Likelihood } \\
\text { Descriptions } \\
\text { Almost certain }\end{array}$} & \multirow{2}{*}{\begin{tabular}{|l} 
Notional \\
Frequency \\
$>10$ times per \\
year
\end{tabular}} & \multicolumn{5}{|c|}{$\begin{array}{l}\text { Typical risk evaluation and response: } \\
\text { Very High - requires immediate risk reduction, and additional assessment using quantitative methods } \\
\text { High - requires immediate review and risk reduction } \\
\text { Moderate - at limit of tolerability, requires additional review and long-term risk reduction } \\
\text { Low and Very Low - tolerable, to be kept under review but no additional risk reduction required }\end{array}$} \\
\hline & & Moderate & High & High & Very High & Very High \\
\hline Likely & $\begin{array}{l}1 \text { to } 10 \text { times per } \\
\text { year }\end{array}$ & Low & Moderate & High & High & Very High \\
\hline Possible & $\begin{array}{l}\text { once every } 1 \text { to } \\
10 \text { years }\end{array}$ & Low & Low & Moderate & High & Very High \\
\hline Unlikely & $\begin{array}{l}\text { once every } 10 \text { to } \\
100 \text { years }\end{array}$ & Very Low & Low & Moderate & High & Very High \\
\hline Very unlikely & $\begin{array}{l}<\text { once every } 100 \\
\text { years }\end{array}$ & Very Low & Low & Moderate & High & High \\
\hline \multicolumn{2}{|c|}{ Consequence Descriptions } & Incidental & Minor & Moderate & Major & Catastrophic \\
\hline \multicolumn{2}{|c|}{ Safety } & First aid incident & Lost time accident & Permanent injury & Fatality & Multiple fatalities \\
\hline \multicolumn{2}{|c|}{ Financial } & $<\$ 100 k$ & $\$ 100 \mathrm{k}$ to $\$ 1 \mathrm{M}$ & $\$ 1 \mathrm{M}$ to $\$ 10 \mathrm{M}$ & $\$ 10 \mathrm{M}$ to $\$ 100 \mathrm{M}$ & $>\$ 100 \mathrm{M}$ \\
\hline
\end{tabular}

(a)

\begin{tabular}{|c|c|c|c|c|c|c|c|}
\hline $\begin{array}{l}\text { Likelihood } \\
\text { Descriptions }\end{array}$ & $\begin{array}{l}\text { Notional } \\
\text { Frequency }\end{array}$ & \multicolumn{6}{|c|}{$\begin{array}{l}\text { Typical risk evaluation and response: } \\
\text { Very High - requires immediate risk reduction, and additional assessment using quantitative methods } \\
\text { High - requires immediate review and risk reduction } \\
\text { Moderate - at limit of tolerability, requires additional review and long-term risk reduction } \\
\text { Low and Very Low - tolerable, to be kept under review but no additional risk reduction required }\end{array}$} \\
\hline Very likely & $>1$ per year & Moderate & High & High & Very High & Very High & Very High \\
\hline Likely & 1 to 0.1 per year & Low & Moderate & High & High & Very High & Very High \\
\hline Moderate & $\begin{array}{l}0.1 \text { to } 0.01 \text { per } \\
\text { year }\end{array}$ & Low & Low & Moderate & High & High & Very High \\
\hline Unlikely & $\begin{array}{l}0.01 \text { to } 0.001 \text { per } \\
\text { year }\end{array}$ & Very Low & Low & Low & Moderate & High & High \\
\hline Very unlikely & $\begin{array}{l}0.001 \text { to } 0.0001 \\
\text { per year }\end{array}$ & Very Low & Very Low & Low & Low & Moderate & High \\
\hline \begin{tabular}{|l} 
Extremely \\
unlikely
\end{tabular} & $<0.0001$ per year & Very Low & Very Low & Very Low & Low & Low & Moderate \\
\hline \multicolumn{2}{|c|}{ Consequence Descriptions } & Incidental & Minor & Moderate & Major & Severe & Catastrophic \\
\hline \multicolumn{2}{|c|}{ Safety } & $\begin{array}{c}<0.001 \text { chance of } \\
\text { fatality }\end{array}$ & $\begin{array}{c}<0.01 \text { chance of } \\
\text { fatality }\end{array}$ & $\begin{array}{c}<0.1 \text { chance of } \\
\text { fatality }\end{array}$ & $<1$ fatality & 1 to 10 fatalities & $>10$ fatalities \\
\hline \multicolumn{2}{|c|}{ Financial } & $<\$ 100 k$ & $\$ 100 \mathrm{k}$ to $\$ 1 \mathrm{M}$ & $\$ 1 \mathrm{M}$ to $\$ 10 \mathrm{M}$ & $\$ 10 \mathrm{M}$ to $\$ 100 \mathrm{M}$ & $\$ 100 \mathrm{M}$ to $\$ 1 \mathrm{~B}$ & $>\$ 1 B$ \\
\hline
\end{tabular}

(b)

Figure 3 (a) Hypothetical non-symmetric $5 \times 5$ risk matrix; (b) Symmetric $6 \times 6$ risk matrix

While risk matrices may look simple to interpret and apply, in our experience that is rarely the case. Risk matrices are often circulated widely across an organisation, but guidance notes that explain the details of how the matrices were developed and how they were meant to be used for risk assessment, risk communication and risk management are often brief and cryptic.

With reference to Figure 3 , risk matrices usually share the following characteristics. Although there are many variations:

- Each cell in the matrix represents a level of risk determined by the product (i.e. multiplication) of the associated likelihood and consequence category values.

- Qualitative risk levels are associated with a required management approach and prioritisation that reflect corporate policies and risk tolerance criteria.

- The likelihood of a negative outcome is usually plotted on the vertical axis, and often contains qualitative or quantitative terms that imply an approximately logarithmic scale of increasing frequency or probability from bottom to top. 
- On many risk matrices the lowest likelihood category does not differentiate between expected frequencies less than 0.01 (or a 1 in 100 chance) per year, and at the high end often considers events that are expected to occur more than 10 times per year.

- Estimates of the magnitude of consequence are usually on the horizontal axis, and often use qualitative or quantitative terms that imply an approximately logarithmic scale of increasing consequence from left to right.

- Different consequence types are assessed separately, and may include assessments of safety, environmental, financial and reputational consequences.

- The risk level assigned is often the highest rated scenario for the different consequence types considered.

- Descriptions of potential safety consequences usually range from first aid incidents to the potential for multiple fatalities. This likely embeds concepts from the 'safety pyramid', which assumes an approximately logarithmic relationship between number of reported safety incidents, serious injuries, and fatalities.

- Sometimes the risk matrices are symmetric, such that if one were to calculate the product of likelihood and consequence along a diagonal line, the risk values along that line would be similar and would be assigned similar qualitative risk ratings. Furthermore, on a symmetric matrix, cells forming a diagonal line from the top left corner to bottom right corner are often designated 'moderate' risk, which is often indicative of an organisation's limit of tolerability.

\section{$4 \quad$ Challenges with use of risk matrices for geohazard assessment}

In the following sections some of the challenges with application of risk matrices for geohazard assessment are explored. Many of these challenges are expected to hold true for the assessment and management of other types of threats, and Oboni and Oboni (2013) and Thomas et al. (2014) provide useful discussions on these matters.

\subsection{What to plot on the likelihood and consequence axes?}

'Likelihood' and 'consequence' are not always explicitly defined or understood by the users of risk matrices. As a result, a question that arises is what 'likelihood' value should be plotted on the vertical axis of the risk matrix. The geohazard likelihood? The likelihood associated with the expected or worst possible outcome? Something in between? Does it matter?

To address the last question first, if the risk matrix is symmetric such that anything plotting along a diagonal from upper left to lower right represents a comparable level of risk that would be evaluated and managed in a comparable way (e.g. Figure 3(b)), perhaps it would not matter too much. But often this is not the case and with a matrix like that in Figure $3(a)$, changes in the selection of factors to plot on the vertical versus horizontal axis can alter the qualitative risk rating.

Sometimes 'likelihood' is set equal to the geohazard event probability, leaving the consequence term to account for estimates of spatial and temporal probability, vulnerability and the number or value of the elements at risk. From a mathematical perspective, this is fine, provided a symmetric risk matrix is used, but a few challenges commonly arise. First, when dealing with safety risk and associated spatial, temporal and vulnerability values, the expected fractional fatalities (or the annual probability of a fatality) may be very small and not readily plotted on the matrix. Second, calibration of geohazard event frequency estimates is usually done through records of events that have occurred. Geohazard events that do not reach, or come close to reaching, elements at risk are often not observed and are under-reported. Third, when grouping most of the factors into the consequence side of the matrix, we find that people often do not properly account for the spatial and/or temporal components which can lead to an overly conservative assessment of risk. 
To help overcome some of these challenges, a common approach is to have 'likelihood' represent the product of hazard probability and spatial probability of impact (i.e. the annual probability that a geohazard will both occur and reach the location where an element at risk may be present, sometimes referred to as the 'encounter probability'), with 'consequence' set equal to the product of temporal probability, vulnerability and value of the element at risk (i.e. the expected loss should a geohazard occur and reach the location where the element at risk may be present). This approach is generally preferable because:

- It allows for the range of applicable likelihood and consequence estimates to be better represented on most risk matrices.

- Databases of observations of when geohazards occur and reach the location where an element may be present tend to be more robust and better for assessment calibration.

- It makes it easier to communicate the components of the risk and to develop and account for effective risk management strategies.

- Geohazard tolerance criteria used by some government agencies and industry associations make use of these 'encounter' probabilities.

To improve consistency and clarity in screening-level geohazard assessment the assessment process can be subdivided into smaller pieces. For example, one matrix can be developed to help determine the likelihood rating and another for the consequence rating. The resulting values can then be plotted on the axes of the risk matrix, and thus determine the risk category. Whittall et al. (2019) and Lato et al. (2019) provide examples of how this approach has been used for geohazard assessment for mineral exploration activities and for railway geohazard management.

For geohazard scenarios that follow a magnitude-frequency distribution, it may be necessary to estimate likelihood and consequence for several event magnitude categories. While risks for simple individual scenarios can easily be plotted on a risk matrix, guidance is often missing on how to combine the risk from different event magnitudes and evaluate and communicate this effectively using a matrix. In some cases, one geohazard magnitude-frequency scenario will dominate the risk estimate such that ignoring all others may not change the risk estimate in a meaningful way; but in many scenarios, this will not be true.

\subsection{How to represent life safety risk?}

The expected safety loss from a geohazard event is usually reported in terms of the expected number of fatalities. This approach is taken because a geohazard event often causes either no injury or a very serious injury or fatality, depending on whether a person is impacted by the event. Relatively few data are available for calibrating safety consequence estimates; the outcomes that are most often reported are for fatalities, with relatively little data on the types and severities of injuries.

When spatial and temporal probabilities and vulnerabilities associated with a geohazard event occurring and impacting a person are taken into consideration, the expected number of fatalities is often less than 1, and sometimes considerably less than 1 . On the hypothetical matrix in Figure 3(a), how would one assess risk for a geohazard scenario with an expected number of fatalities of 0.02 should the geohazard occur? Should we assume this is somehow equivalent to a near-miss or lost-time accident?

Many risk matrices do not explicitly consider temporal probabilities as a factor in the expected negative outcomes to workers or the public exposed to geohazards; but for many facility types, temporal probability may be extremely small. For example, a hazardous section of a service road might be occupied for a few seconds per day by a small maintenance crew, while nearby camp facilities might be occupied by tens or hundreds of people on a nearly full-time basis. In theory, the worst possible outcome for a geohazard event at either location could include multiple fatalities, while in reality, the expected number of fatalities should a geohazard occur along the service road might be a small fraction of a single fatality because exposure time is so low, compared to an expectation that multiple fatalities could reasonably occur if a geohazard event 
impacted the camp. Proper accounting of spatial and temporal probabilities allows for greater insight into the most efficient and effective ways to reduce safety risk.

\subsection{Alignment with emerging international guidance on risk tolerance}

In quantitative assessment of safety risk, societal risk estimates are often presented on graphs showing the expected frequency and cumulative number of fatalities, referred to as $\mathrm{F}-\mathrm{N}$ curves. F-N curves were originally developed for nuclear hazards (Kendall et al. 1977), where the purpose was to illustrate risk tolerance thresholds reflecting societal aversion to multiple fatalities during a single catastrophic event.

The graph in Figure 4 is representative of F-N curves used for risk-informed decision-making by several organisations including Canadian and US dam safety organisations, and by Hong Kong and some local governments in Canada and New Zealand for landslide safety assessment (Porter et al. 2017). The graph is subdivided into four areas representing unacceptable risk, tolerable risk which should be reduced further if practicable according to the as low as reasonably practicable (ALARP) principle, risk that is considered broadly acceptable, and a region of low probability but with the potential for $>1,000$ fatalities that requires intense scrutiny. From the perspective of potential loss of life, a project or activity might be approved if it can be demonstrated that risks fall in the ALARP or broadly acceptable regions on an F-N graph.

As noted in Figure 4, the limit of tolerability is usually anchored by a point where the annual frequency of one or more fatalities is 1 in $1,000\left(10^{-3}\right)$, and this tolerable frequency drops by an order of magnitude for each tenfold increase in the expected number of fatalities. Life safety risk estimates reported on corporate risk matrices reflect some measure of societal or group risk. The risk tolerance criteria embedded in these matrices sometimes loosely align with criteria like those presented in Figure 4, but often they do not, and rarely is it clear from the accompanying guidance notes if departures from such criteria are deliberate.

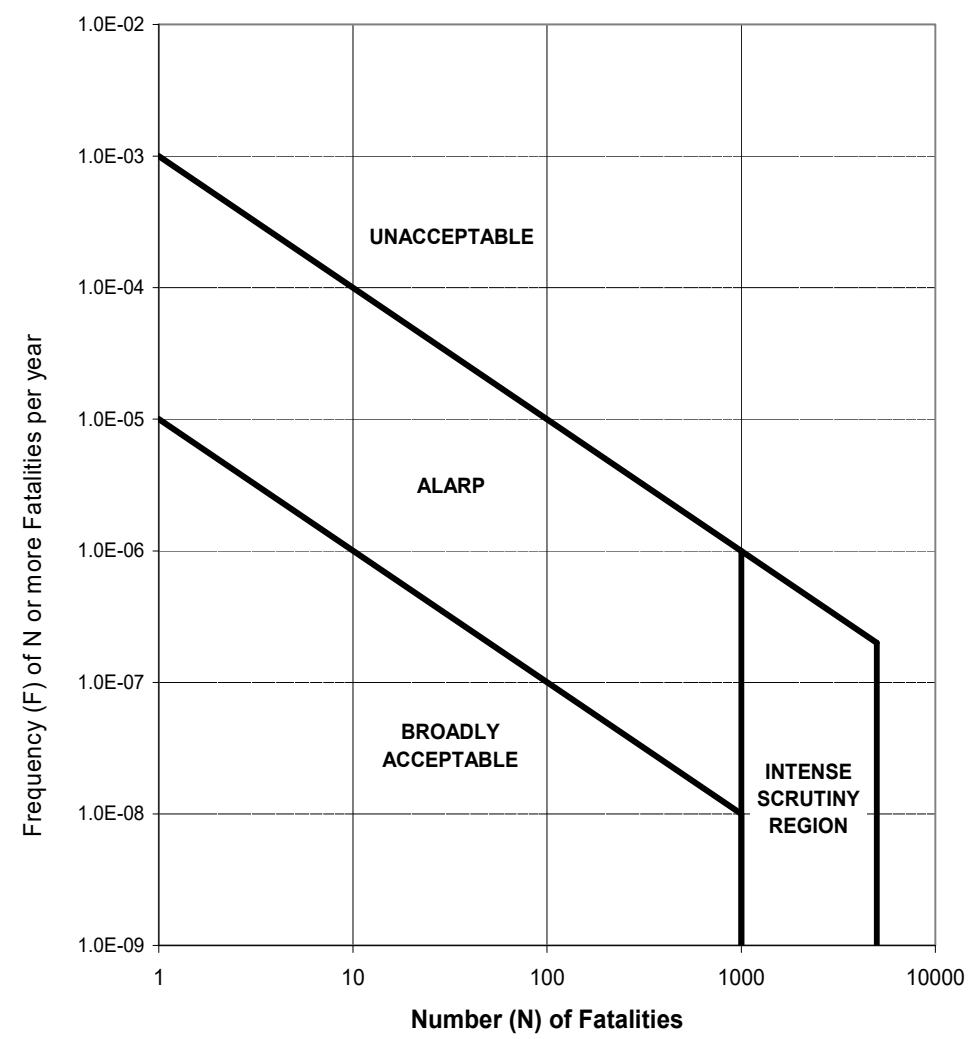

Figure 4 Example F-N graph for evaluating societal risk (Geotechnical Engineering Office 1998)

In addition to societal or group risk, consensus is emerging in geohazard practice that risk of death for individuals most at risk should be less than 1:10,000 per year for existing developments. This value approximately aligns the annual probability of being in a fatal car accident, and the mortality of (western) children aged five to nine (Porter et al. 2009). Several local governments and dam safety organisations target 
risks to individuals of less than 1:100,000 per year for new developments (Porter et al. 2017). Risk matrices are not set up well to report estimates of individual risk, and risk tolerance criteria embedded in the matrices are not generally intended to be used for assessment of individual risk. If required, these estimates need to be reported outside of the risk matrix.

In general, individuals and society have a higher tolerance for risks that are voluntary compared to risks that are considered involuntary. Some geohazard practitioners have postulated that risks to workers from landslides might be considered voluntary because employees know that benefits (income) are, at least, partial compensation for the perceived risks, provided that the risks are adequately understood. For example, Bunce and Martin (2011) suggested that a risk of fatality of 1:10,000 per annum might represent a reasonable target for Canadian train crews operating in landslide-prone terrain. Perhaps this reasoning is why some corporate risk matrices differentiate between impacts to employees and impacts to the public, but guidance notes that might accompany such matrices are usually silent on this matter. It is the authors' observation that workers interpret their employer's duty to provide a safe workplace to mean geohazard risks are being handled by management, leaving a potentially false perception of safety.

\subsection{Assessment of low-frequency, high-consequence events}

The authors often encounter corporate risk matrices that assign all events with less than a 1 in 100 chance per year to the same likelihood category, similar to the matrix in Figure 3(a). However, some geohazard processes and geotechnical failures can pose very high potential consequences in terms of safety and business interruption loss, but tend to occur infrequently. Examples might include sites exposed to large but infrequent debris flows, rock avalanches, earthquakes or floods. The matrix in Figure 3(a) does not lend itself well to an examination of these types of hazards and risks, since most scenarios tend to plot as a low-probability, high-consequent event. This makes it difficult to represent or communicate differences in these 'very high' risk scenarios, including the potential benefits of mitigation options. Matrices that account for lower likelihood and higher consequence ranges, such as illustrated in Figure 3(b), help overcome some of these limitations. Corporate policy requirements that all 'very high' risk scenarios undergo more detailed review using methods such as targeted quantitative risk assessment would further improve risk-informed decision-making for these low-frequency, high-probability scenarios.

A related issue with risk matrix and other approaches to assessment of low-frequency events is that frequencies are often assigned by group consensus based on the group members' experience or lack thereof with these infrequent events. It is easy to be fooled into thinking that because an event has not occurred at a specific project site, the probability must be very low. This can be a very dangerous assumption.

Even with rigorous assessment methods, the uncertainties associated with risk estimates for low-frequency, high-consequent events can be very large. Probability distribution functions for both geohazard magnitude and consequence can be difficult to define and may exhibit 'fat-tail' or power law properties such that extreme events may occur more frequently than predicted using a normal exponential distribution (e.g. Nishenko \& Barton 1995; Mechler 2016). There is a tendency in the guidance that often accompanies risk matrices to think in terms of expected or reasonably credible losses, but because of these 'fat-tail' properties, the likelihood of extreme loss scenarios can be higher than anticipated and may dominate the risk profile. Adequately assessing and communicating these uncertainties within the confines of a risk matrix approach can be challenging.

\subsection{Assessment scale and geohazard interdependencies}

A significant limitation with risk matrices, in the authors' experience, is a lack of guidance on how they are to be applied at different project scales. Was the matrix developed for the executive team to assess the summation of risks for entire projects and all associated infrastructure? Was it intended to be used by a mine manager to assess the summation of all risks associated with specific facilities? Was it intended to be used by the foreman for assessment of individual geohazard threats? Or was it intended to be used by work teams to help assess and manage their risks on a daily basis? Each scenario involves a different scale of assessment. 
Geohazard risk assessment almost always starts with an inventory and assessment of individual hazards. Using the techniques outlined in this paper, it is relatively straightforward to estimate risks associated with individual hazards and to communicate and evaluate those risks using a risk matrix. If individual geohazards are statistically independent from each other, it is also easy to sum up the risks associated with multiple geohazards affecting an asset, and it is possible to present the estimate of combined risk on a risk matrix, although in the authors' experience, this is often not done.

However, geohazards often share common triggering events and are rarely perfectly independent of each other. This means that it is not unusual for multiple geohazards to occur in response to a triggering event which can impact service outage time and complicates the estimate of consequences. To further complicate matters, the financial impact of business interruption per unit of time is usually not linear. Consequently, the examination and reporting of a summation of risk arising from multiple geohazards affecting a facility or infrastructure can be quite complex.

The main point we are trying to make here is that multiple system components that operate in series can pose high risk, even though risk for individual components might be relatively low. So, if a risk matrix intended for assessment of total system risk is used to evaluate risk at individual geohazard sites, the resultant risk ratings for the individual sites could be very misleading. If the risk estimates for the individual sites are low, the need for targeted quantitative assessment might not be triggered, and some of the complicating factors outlined earlier might not be addressed.

\subsection{The variable and dynamic nature of geohazard risk}

The likelihood of geohazard occurrence is not static and may increase in response to time (e.g. as a result of progressive failure), construction activities (e.g. loss of support from excavations, increases in loads from placement of fills, and alteration of drainage), forest fires and changes in land cover, weather, snow accumulation, climate change and other factors. Alternatively, stabilisation efforts or other factors may result in a decrease in geohazard likelihood. Consequences can also change over time. For example, if a small seasonal exploration camp evolves into a year-round construction camp, the number of potentially exposed workers and duration of exposure both increase.

Given the variable and dynamic nature of geohazard risk, it is important to keep geohazard risk estimates under review and updated through regular inspections, monitoring observations or in response to climatic events. Risk matrices can be used to support these efforts provided the limitations outlined earlier are understood. For complex systems and geohazard scenarios, software solutions may be needed to manage the data feeding into the risk assessment and to aid in updating the risk ratings following inspections or in response to monitoring observations.

\section{$5 \quad$ Guidance}

In light of the challenges associated with use of risk matrices for geohazard management, we offer this summary guidance for consideration in practice.

It is important to understand the origins and purpose of each risk matrix. Guidance documents should accompany the risk matrix and the owner of the risk matrix should be clearly identified.

Users of the risk matrix should avoid the temptation to arbitrarily change or adapt it. Considerable thought will have gone into developing a proper risk matrix; if it does not appear to meet your needs, there is a good chance it was never intended to be used in the way you are attempting. Concerns should be documented and discussed with the owner of the risk matrix.

Risk matrix owners should be familiar with emerging international risk tolerance criteria for life safety, and other regulatory safety requirements and standards of practice, and note where risk matrices appear to be in conflict with these criteria. 
Because of the many factors that feed into estimation of likelihood and consequence, matrix users should look for ways to improve consistency and clarity on how these factors are defined and assigned. Development of other matrices to assign each parameter separately before combining in the risk matrix is one approach that may be helpful. For more complex systems or hazard scenarios, use of targeted quantitative risk assessment should be considered.

Geohazard risk management will generally benefit from working with the risk matrix owner to include greater granularity for low-frequency, high-consequence events, consistent methods for accounting for spatial and temporal probabilities, and alignment with international safety risk tolerance criteria.

Risk is scale-dependent. An individual geohazard site that does not rank high on a risk matrix may be a significant contributor to a system risk that the organisation would find unacceptable.

Risk assignments will change in time as the project develops, as land-use changes, and in response to climatic events. Connecting monitoring data, triggering conditions, and spatial and temporal probability estimates to a 'live' system can allow risk to be more readily updated and accurately portrayed.

\section{Acknowledgement}

Helpful peer review of this manuscript was provided by several colleagues including Roy Mayfield, Jorge Troncoso, Michael Henderson and Angela Kupper.

\section{References}

Bunce, C \& Martin, D 2011, 'Risk estimation for railways exposed to landslides', Proceedings of the 5th Canadian GeoHazards Conference, Canadian Geotechnical Society, Richmond.

Geotechnical Engineering Office 1998, Landslides and Boulder Falls from Natural Terrain: Interim Risk Guidelines, GEO Report No. 75, Geotechnical Engineering Office, Kowloon.

Hungr, O, Hazzard, J \& Evans, SG 1999, 'Magnitude and frequency of rock falls and rock slides along the main transportation corridors of southwestern British Columbia', Canadian Geotechnical Journal, vol. 36, pp. 224-238.

Kendall, H, Hubbard, R, Minor, G \& Bryan, W 1977, The Risks of Nuclear Power Reactors: A Review of the NRC Reactor Safety Study, WASH-1400, Union of Concerned Scientists, Cambridge.

Lato, M, Quinn, P, Porter, M, Newton, S, Dixon, R, Wessels, SDN, Wessels, L, Sirois, D \& Leveque, M 2019, 'Geohazard risk management for linear transportation', in J Wesseloo (ed.), Proceedings of The First International Conference on Mining Geomechanical Risk, Australian Centre for Geomechanics, Perth, pp. 323-336.

Mechler, R 2016, 'Reviewing estimates of the economic efficiency of disaster risk management: opportunities and limitations of using risk-based cost-benefit analysis', Natural Hazards, vol. 81, issue 3, pp. 2121-2147.

Nishenko, SP \& Barton, CC 1995, Scaling Laws for Natural Disaster Fatalities, Open File Report 95-67, US Geological Survey, Reston.

Oboni, F \& Oboni, C 2013, What You Need to Know About Risk Management Methods: is it True That PIGs Fly When Evaluating Risks of Projects, Operations and Corporations?, Riskope International, Vancouver.

Porter, M, Jakob, M \& Holm, K 2009, 'Proposed landslide risk tolerance criteria', Proceedings of the 2009 Canadian Geotechnical Conference, Canadian Geotechnical Society, Richmond.

Porter, M, Jakob, M, Holm, K \& McDougall, S 2017 'Risk-based landslide safety assessments in Canada', in JA De Gaff \& A Shakoor Proceedings of the 3rd North American Symposium on Landslides, Association of Environmental \& Engineering Geologists, Lexington, pp. 574-584.

Porter, M, Leir, M, Baumgard, A \& Ferris, G 2014, 'Integrating terrain and geohazard knowledge into the pipeline lifecycle', Proceedings of the 6th Canadian GeoHazards Conference, Canadian Geotechnical Society, Richmond.

Thomas, P, Bratvold, RB \& Bickel, JE 2014, 'The risk of using risk matrices', Society of Petroleum Engineers Economics and Management, vol. 6, no. 2, pp. 56-66.

Whittall, J, Quinn, P, Lato, M, Porter, M, Bowden, B, Drew, J \& Croaker, M 2019, 'Managing geohazard risk during mineral exploration at remote locations in rugged terrain and tropical environments', in J Wesseloo (ed.), Proceedings of The First International Conference on Mining Geomechanical Risk, Australian Centre for Geomechanics, Perth, pp. 493-504. 
